\title{
REDUCED CITRATE SYNTHASE ACTIVITY EFFECT ON OXYGEN CONSUMPTION RATES IN ISOLATED MITOCHONDRIA FROM MICE LIVER AND MUSCLES
}

\author{
Andrej Fokin ${ }^{1}$, Rasa Žūkienè2, Aivaras Ratkevičius ${ }^{1}$ \\ Lithuanian Sports University', Kaunas, Lithuania \\ Vytautas Magnus University², Kaunas, Lithuania
}

\begin{abstract}
Background. Liver and skeletal muscles play the major role in metabolism. Mitochondria are of particular importance in functioning of these organs. We tested the hypothesis that reduced citrate synthase (CS) activity could induce improved fatty substrate and carbohydrate oxidation in mitochondria extracted from liver and hind limb muscles of mice.

Methods. Eight mice each of 12-week-old control C57B6/J (B6) and congenic B6.A-(rs3676616-D10Utsw1)/ Kjn (B6.A) mice were studied. The mitochondria were isolated by differential centrifugation method followed by assessment of mitochondrial respiration and citrate synthase (CS) activity. Mitochondrial respiration was measured as oxygen consumption with Clark-type oxygen electrode by using polarography system. CS enzyme activity was measured spectrophotometrically.

Results. The activity of CS was by $\sim 32 \%$ lower for mitochondria for B6.A compared to B6 mice $(603.9 \pm 135.6 \mathrm{U} / \mathrm{g}$ and $894.2 \pm 193.2 \mathrm{U} / \mathrm{g}$, respectively). Mitochondrial respiration did not differ significantly between the strains.

Conclusions. $30 \%$ reduction in citrate synthase activity does not impair mitochondrial respiration.
\end{abstract}

Keywords: mitochondrial respiration, insulin resistance, $\beta$-oxidation.

\section{INTRODUCTION}

$\mathrm{M}$ itochondrial dysfunction might contribute to such conditions as obesity, insulin resistance and type II diabetes (Christe et al., 2013; Yang et al., 2012). Both obesity and type 2 diabetes are associated with poor performance of mitochondria (Houmard, 2008). The misbalance between $\beta$-oxidation of fatty acids and substrate flux through Krebs cycle seems to be of special importance for functioning of mitochondria and, therefore, the development of obesity and diabetes (Koves et al., 2008). It means that the balance between oxidation of fatty acids and oxidation of carbohydrates in citric acid cycle is one of the common mechanisms to regulate performance of mitochondria. There is evidence that citrate or citric acid, an intermediate of the mitochondrial Krebs cycle, plays a role in controlling this balance (Ruderman, Saha, Vavvas, \& Witters, 1999). Cytosolic citrate is converted by ATP citrate lyase (ACL) to acetyl CoA, the substrate for acetyl CoA carboxylase (ACC) in the synthesis of malonyl CoA. Malonyl CoA can inhibit carnitine palmitoyl transferase 1 (CPT) and thus interfere in with fatty acid oxidation. Low rates of fatty acid oxidation contribute to metabolic disorders. It can be speculated that reduced levels of CS activity might be beneficial in promoting fatty acid oxidation under conditions of excessive substrate supply.

Citrate synthase (CS) has often been used as a mitochondrial marker in both animal and human studies (Hamilton \& Booth, 2000; Rabol, Boushel, $\&$ Dela, 2006). Mammalian CS is encoded by a single nuclear gene. After translation in the cytosol, CS is 
transported into the mitochondrial matrix, where it functions as the first and rate-limiting enzyme of the citric acid cycle and thus plays a decisive role in regulating energy generation and ROS production of mitochondrial respiration. A missense mutation of Cs might therefore alter mitochondrial function (Johnson, Gagnon, Longo-Guess, \& Kane, 2012). Liver, skeletal muscles, adipose tissue and pancreas are believed to play the major role in insulin resistance (Bouderba et al., 2012). In current study we have tested mitochondrial oxidation of different substrates in liver and skeletal muscles. We investigated mitochondrial respiration in mice with $\mathrm{H} 55 \mathrm{~N}$ polymorphism which is associated with reduced CS activity (Ratkevicius et al., 2010).

The aim of the study was to test the hypothesis that low citrate synthase (CS) activity could improve fatty substrate and carbohydrate oxidation in mitochondria. Thus we investigated whether CS activity and respiration differ between mitochondria derived from C57BL/6J (B6) strain and congenic B6.A-(rs3676616-D10Utsw1)/KjnB6 (B6.A) strains of mice. B6.A strain carries the A/J allele in the genomic region containing the $C s$ gene on otherwise B6 strain background.

\section{METHODS}

Animals. All the procedures were approved by the Lithuanian State Food and Veterinary Service (No. 0223). Mice were kept in standard cages (cage dimensions: $267 \times 207 \times 140 \mathrm{~mm})$ at $20-22^{\circ} \mathrm{C}$ temperature and $55 \pm 10 \%$ humidity with $12 / 12-\mathrm{h}$ light/dark cycle. Mice fed for standard rodent diet $(58.0 \% \mathrm{kcal}$ from carbohydrate, $28.5 \% \mathrm{kcal}$ from protein, $13.5 \% \mathrm{kcal}$ from fat; LabDiet 5001, LabDiet, St. Louis, USA) and received tap water ad libitum. For mitochondria experiment 12 week-old B6 and B6.A mice were used. B6 and eight B6.A mice of male and female sex ( $n=8$ in each group) were studied.

Mitochondria isolation and respiration. Following euthanasia by the cervical dislocation, liver and hind limb muscles were quickly excised and placed into separate $80 \mathrm{ml}$ ice cold $0.9 \% \mathrm{KCl}$ solution. After $3 \mathrm{~min}$, liver and muscles were briefly minced with surgical scissors. Additionally, muscles were incubated for $5 \mathrm{~min}$ in ice cold isolation medium A (150 mM sucrose, $75 \mathrm{mM} \mathrm{KCl}$, $50 \mathrm{mM} \mathrm{KH}_{2} \mathrm{PO}_{4}, 5 \mathrm{mM} \mathrm{MgCl}, 1 \mathrm{mM}$ EGTA, $\mathrm{pH}=$ 7.4) supplemented with $2 \mathrm{mg} / \mathrm{ml}$ proteinase (type XXIV, Sigma P8038). Liver was filled homogenized in medium $\mathrm{H}(250 \mathrm{mM}$ sucrose, $10 \mathrm{mM}$ TRIS,
3 mM EGTA, $\mathrm{pH}=7.7$ ) by electric Potter-Elvehjem homogenizer with 10 strokes at $750 \mathrm{rpm}$. After the incubation, $20 \mathrm{ml}$ of ice cold isolation medium $\mathrm{B}$ (250 mM sucrose, $20 \mathrm{mM}$ MOPS, $0.1 \mathrm{mM}$ EGTA, $\mathrm{pH}=7.4$ ) supplemented with $1 \mathrm{mg} / \mathrm{ml}$ of BSA was added into minced muscles and the final mix was homogenized with 10 strokes at $750 \mathrm{rpm}$. Homogenates were transferred to the centrifuge tubes. Mitochondria were isolated by differential centrifugation (Zukiene, Nauciene, Ciapaite, \& Mildaziene, 2010). For liver mitochondria there were 3 steps of centrifugation: $800 \mathrm{x}$ g for $5 \mathrm{~min}$, $6800 \mathrm{x} g$ for $10 \mathrm{~min}$ and $6800 \mathrm{x} \mathrm{g}$ for $10 \mathrm{~min}$, for muscle mitochondria: $800 \mathrm{x} \mathrm{g}$ for $10 \mathrm{~min}$, $10000 \mathrm{x} \mathrm{g}$ for $10 \mathrm{~min}$ and $10000 \mathrm{x} \mathrm{g}$ for $10 \mathrm{~min}$. After the 2nd centrifugation the supernatant was removed and $10 \mathrm{ml}$ of ice cold isolation medium $B$ was added to re-suspend the muscle mitochondrial pellet. In case of liver mitochondria, medium M ( $250 \mathrm{mM}$ sucrose, $5 \mathrm{mM}$ TRIS, $\mathrm{pH}=7.3$ ) was added to re-suspend mitochondrial pellet. Mitochondrial pellets were kept on ice throughout the experiment. The protein concentration was determined by a modified burette method using bovine serum albumin (BSA) as a standard. Final mitochondrial suspensions were used immediately for respiration measurement or stored at $-80^{\circ} \mathrm{C}$ until enzyme activity analysis.

Mitochondrial respiration was measured as oxygen consumption $\left(\mathrm{O}_{2} \mathrm{nmol} \mathrm{min} \mathrm{mg}^{-1} \mathrm{mg}^{-1}\right.$ protein, VO2) at $37^{\circ} \mathrm{C}$ in $1.5 \mathrm{ml}$ glass vessel equipped with Clark-type oxygen electrode by using polarography system. The following respiratory substrates were used: 1) $5 \mathrm{mM}$ glutamate plus $5 \mathrm{mM}$ malate $(\mathrm{G}+$ $\mathrm{M})$; 2) $5 \mathrm{mM}$ pyruvate plus $5 \mathrm{mM}$ malate $(\mathrm{P}+$ M); 3) $0.25 \mathrm{mM}$ malate plus $0.005 \mathrm{mM}$ palmitoylcarnitine $(\mathrm{M}+\mathrm{PC})$; 4) $5 \mathrm{mM}$ glutamate plus $5 \mathrm{mM}$ malate plus $0.005 \mathrm{mM}$ palmitoyl-carnitine $(\mathrm{GM}+\mathrm{PC})$; 5) $5 \mathrm{mM}$ pyruvate plus $5 \mathrm{mM}$ malate + $0.005 \mathrm{mM}$ palmitoyl-carnitine (PM + PC); 6) $5 \mathrm{mM}$ succinate plus $0.001 \mathrm{mM}$ rotenone (Suc + Ro). Rotenone inhibits role respiration complex I and was used in to measure $\mathrm{VO}_{2}$ which is associated with respiration complex II (Bouderba et al., 2012). $1 \mathrm{ml}$ of incubation solution 6 (IT6) $(\mathrm{KCl} 110 \mathrm{mM}$, creatine monohydrate $50 \mathrm{mM}$, TRIS $20 \mathrm{mM}$, $\mathrm{KH}_{2} \mathrm{PO}_{4} 5 \mathrm{mM}, \mathrm{Mg}\left(\mathrm{MgCl}_{2} \cdot 6 \mathrm{H}_{2} \mathrm{O}\right) 2.5 \mathrm{mM}, \mathrm{pH}=$ 7.2) was used in the experiments. Mitochondrial non-phosphorylating state 2 respiration (V2) was initiated by adding mitochondria into IT6 containing substrates. State 3 respiration (V3) was initiated by adding $1 \mathrm{mM}$ of ATP which is constantly converted to ADP by creatine- creatine phosphokinase system in the medium. 
Citrate synthase activity assay. CS activity was measured as in our previous studies (Ratkevicius et al., 2010). Briefly, $10 \mathrm{ml}$ of mitochondria lysate was added to start the reaction in $990 \mathrm{ml}$ of reaction reagent which then consisted of $100 \mathrm{mM}$ triethanolamine-HCl, DTNB $(100 \mu \mathrm{M})$, $0.25 \%$ Triton-X (vol/vol), $0.5 \mathrm{mM}$ oxaloacetate, $0.31 \mathrm{mM}$ acetyl CoA with $\mathrm{pH}$ adjusted to 8.0. The wave length of the spectrophotometer was set $412 \mathrm{~nm}$ and the molar extinction coefficient of $13,600 \mathrm{M}^{-1} \cdot \mathrm{cm}^{-1}$ was used in calculations of the maximum CS activity (Vmax) during the first 2 min of the reaction at room temperature $\left(\sim 21^{\circ} \mathrm{C}\right)$. CS from porcine heart was used as a standard (C3260-200UN, Sigma-Aldrich, UK) for assay calibration. Protein concentration of the mitochondrial lysates was determined using the Bradford Assay (Bio-rad, Hertfordshire, UK). CS activity was expressed in units or $\mathrm{U}\left(\mathrm{mmol} \mathrm{min}^{-1}\right)$ per gram $(\mathrm{g})$ protein.

Statistical analysis. 2-way ANOVA test and Bonferroni post-test were used to evaluate differences between the strains in ATP stimulated mitochondrial respiration. Unpaired $T$-test was performed to observe enzyme activity differences. Values of $p<.05$ were considered as statistically significant. Results are presented as mean $\pm S D$.

\section{RESULTS}

CS activity was reduced by $32 \%$ in mitochondrial samples (cor. spec. 894.2 \pm 193.2 in B6 mitochondria compared to $603.9 \pm 135.6 \mathrm{U} / \mathrm{g}$ in B6.A mitochondria) in mice with CS polymorphism (B6.A, $n=8)$ compared to control $(\mathrm{B} 6, n=8)$, $p<.05$ (Figure 1). There was no difference between male and female mice.

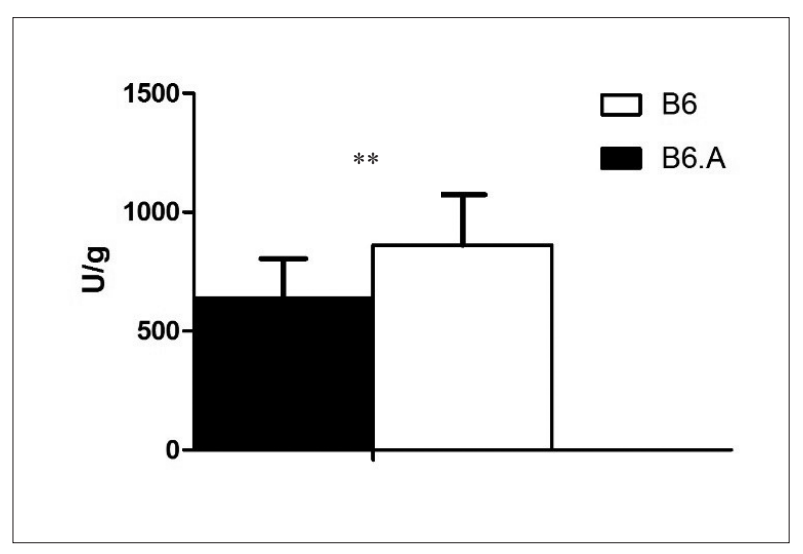

Figure 1. Citrate synthase' activity (U/g) in B6 and B6.A mice mitochondria

Note. $* * p<.05$.
No significant differences in V3 were observed between mitochondria from B6 and B6.A liver or muscles (Figures 2 and 3, respectively). There was a tendency of increased respiration with PM and $\mathrm{PM}+\mathrm{PC}$ substrates in B6.A mice compared to B6 both in liver and muscles mitochondria.

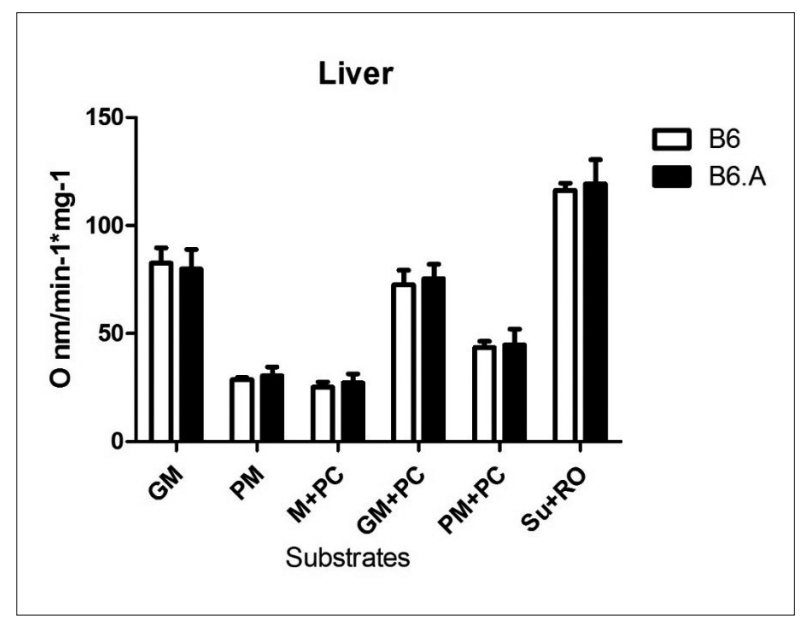

Figure 2. Comparison of three liver mitochondria respiration states between B6 and B6.A mice

Note. The following substrates were used: GM - glutamate plus malate, $\mathrm{PM}$ - pyruvate plus malate, $\mathrm{M}+\mathrm{PC}$ - malate plus palmitoylcarnitine, $\mathrm{Su}+\mathrm{RO}-$ succinate plus rotenone.

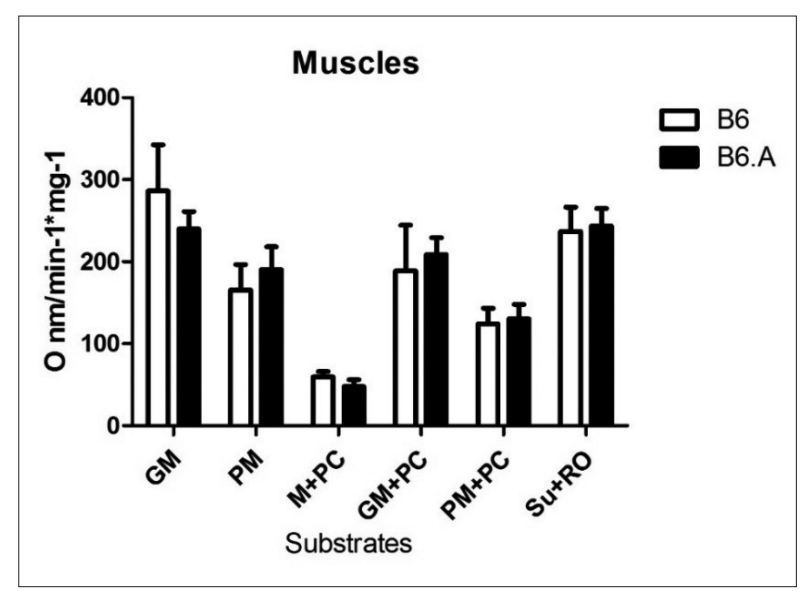

Figure 3. Comparison of three muscle mitochondria respiration states between B6 and B6.A mice

Note. The following substrates were used: GM - glutamate plus malate, $\mathrm{PM}$ - pyruvate plus malate, $\mathrm{M}+\mathrm{PC}$ - malate plus palmitoylcarnitine, $\mathrm{Su}+\mathrm{RO}-$ succinate plus rotenone.

In liver mitochondria, V3 was higher with $\mathrm{PM}+\mathrm{PC}$ substrates compared to PM substrate in both strains $(p<.05)$ (Figure 2). V3 with $\mathrm{GM}+$ PC compared to GM without an addition of PC fatty substrate remained constant in both strain and did not differ (B6: GM $82.53 \pm 17.62$ and GM + PC $72.58 \pm 13.38 \mathrm{~min}^{-1} \mathrm{mg}^{-1}$ protein, respectively; B6.A: GM $79.83 \pm 24.14$ and GM + PC $75.48 \pm$ $17.38 \mathrm{~min}^{-1} \mathrm{mg}^{-1}$ protein, respectively). $\mathrm{VO} 2$ at 
$\mathrm{V} 3$ under $\mathrm{SU}+\mathrm{RO}$ conditions was higher than measured with other substrates in both B6 and B6.A mice liver mitochondria $(p<.05)$.

In muscle mitochondria, unlike in liver mitochondria, V3 with PM + PC was lower compared to PM in both mice strain $(p<.05)$ (Figure 3). Respiration V3 with GM + PC compared to GM was also lower in both strains, but not statistically significantly. The respiration of $\mathrm{SU}+\mathrm{RO}$ was high as in liver mitochondria in $\mathrm{B} 6$ and in B6.A mice. With mitochondria isolated from muscle, we also noticed a net decline in respiratory chain activity under $\mathrm{M}+\mathrm{PC}$ condition (low $\mathrm{VO}_{2}$ rates compared to respiration with other substrates, Figure 3).

\section{DISCUSSION}

The main aim of the study was to show if low citrate synthase (CS) activity could improve fatty substrate and carbohydrate oxidation in mitochondria. We studied CS activity and respiration in mitochondria derived from B6 and B6.A mice. B6.A strain carries the $\mathrm{A} / \mathrm{J}$ allele in the genomic region containing the $\mathrm{Cs}$ gene on otherwise B6 strain background. Previous studies showed that $\mathrm{A} / \mathrm{J}$ mice show $50-65 \%$ reduction in muscle tissue derived CS activity compared to other mouse strains despite similar levels of Cs mRNA and lack of differences in CS and cytochrome c protein content (Ratkevicius et al., 2010). In agreement with these results, we found $\sim 32 \%$ lower mitochondrial CS activity in B6.A mice compared to B6 mice. However, we did not observe any significant difference in mitochondrial respiration between these strains. We measured CS activity without any prior interventions. There is some evidence to suggest that CS activity increases after cycling to exhaustion at $75 \%$ of peak $\mathrm{O}_{2}$ uptake, whereas activities of marker enzymes for fatty acid oxidation ( $\beta$-hydroxyacyl-CoA dehydrogenase) and glycolysis (phosphofructokinase) were unaffected (Tonkonogi, Harris, \& Sahlin, 1997). This suggests that CS activity might vary before and after various interventions.

We did not observe any significant differences in mitochondrial respiration between B6 and B6.A mice with reduced CS activity. Mitochondrial respiration differed significantly in the presence and in the absence of palmitoylcarnitine (PC) which is a fatty substrate. Indeed, carbohydrate oxidation in liver mitochondria was faster with addition of PC (PM + PC) compared to PM alone. Those differences might exist because of a strong link between $\beta$-oxidation of fatty substrates and oxidation of carbohydrates in citric acid cycle (Rogge, 2009). In muscle, mitochondrial respiration inhibition with $\mathrm{PC}$ can be explained by ANT inhibition (Ciapaite et al., 2006).

In isolated mitochondria oxygen consumption rates and mechanics differ from intact cells. There are several studies which show significant difference in $\mathrm{VO}_{2}$ of mammals before and after high fat diet (Bourbera et al., 2012). In summary, our study did not reveal any association between reduced CS activity and mitochondria respiration rates in mice under normal conditions without any external interventions, e.g. hyperthermia (Zukiene et al., 2010).

\section{CONCLUSIONS}

1. B6.A-(rs3676616-D10Utsw1)/KjnB6 mice have reduced citrate szynthase activity in comparison with $\mathrm{C} 57 \mathrm{BL} / 6 \mathrm{~J}$ mice.

2. Oxygen consumption rates in liver and muscles mitochondria were similar in B6.A(rs3676616-D10Utsw1)/KjnB6 and in C57BL/6J mice.

\section{REFERENCES}

Bouderba, S., Sanz, M. N., Sanchez-Martin, C., ElMir, M. Y., Villanueva, G. R., Detaille, D., \& Koceir, E. A. (2012). Hepatic mitochondrial alterations and increased oxidative stress in nutritional diabetes-prone Psammomys obesus model. Experimental Diabetes Research, 2012, 430176. doi: 10.1155/2012/430176

Christe, M., Hirzel, E., Lindinger, A., Kern, B., von Flue, M., Peterli, R., . . Lindinger, P. W. (2013). Obesity affects mitochondrial citrate synthase in human omental adipose tissue. ISRN Obesity, 2013, 826027. doi: $10.1155 / 2013 / 826027$
Ciapaite, J., Bakker, S. J., Diamant, M., van Eikenhorst, G., Heine, R. J., Westerhoff, H. V., \& Krab, K. (2006). Metabolic control of mitochondrial properties by adenine nucleotide translocator determines palmitoylCoA effects. Implications for a mechanism linking obesity and type 2 diabetes. FEBS Journal, 273(23), 5288-5302. doi: 10.1111/j.1742-4658.2006.05523.x

Hamilton, M. T., \& Booth, F. W. (2000). Skeletal muscle adaptation to exercise: A century of progress. Journal of Applied Physiology, 88(1), 327-331. 
Houmard, J. A. (2008). Intramuscular lipid oxidation and obesity. American Journal of Physiology. Regulatory, Integrative and Comparative Physiology, 294(4), R1111-1116. doi: 10.1152/ajpregu.00396.2007

Johnson, K. R., Gagnon, L. H., Longo-Guess, C., \& Kane, K. L. (2012). Association of a citrate synthase missense mutation with age-related hearing loss in A/J mice. Neurobiology of Aging, 33(8), 1720-1729. doi: 10.1016/j.neurobiolaging.2011.05.009

Koves, T. R., Ussher, J. R., Noland, R. C., Slentz, D., Mosedale, M., Ilkayeva, O., . . Muoio, D. M. (2008). Mitochondrial overload and incomplete fatty acid oxidation contribute to skeletal muscle insulin resistance. Cell Metabolism, 7(1), 45-56. doi: 10.1016/j. cmet.2007.10.013

Rabol, R., Boushel, R., \& Dela, F. (2006). Mitochondrial oxidative function and type 2 diabetes. Applied Physiology, Nutrition, and Metabolism, 31(6), 675-683. doi: 10.1139/h06-071

Ratkevicius, A., Carroll, A. M., Kilikevicius, A., Venckunas, T., McDermott, K. T., Gray, S. R., . . . Lionikas, A. (2010). H55N polymorphism as a likely cause of variation in citrate synthase activity of mouse skeletal muscle. Physiological Genomics, 42A(2), 96102. doi: 10.1152/physiolgenomics.00066.2010
Rogge, M. M. (2009). The role of impaired mitochondrial lipid oxidation in obesity. Biological Research for Nursing, 10(4), 356-373. doi: 10.1177/1099800408329408

Ruderman, N. B., Saha, A. K., Vavvas, D., \& Witters, L. A. (1999). Malonyl-CoA, fuel sensing, and insulin resistance. American Journal of Physiology, 276(1 Pt 1), E1-E18.

Tonkonogi, M., Harris, B., \& Sahlin, K. (1997). Increased activity of citrate synthase in human skeletal muscle after a single bout of prolonged exercise. Acta Physiologica Scandinavica, 161(3), 435-436. doi: 10.1046/j.1365-201X.1997.00233.X

Yang, C., Aye, C. C., Li, X., Diaz Ramos, A., Zorzano, A., \& Mora, S. (2012). Mitochondrial dysfunction in insulin resistance: differential contributions of chronic insulin and saturated fatty acid exposure in muscle cells. Bioscience Reports, 32(5), 465-478. doi: 10.1042/ BSR20120034

Zukiene, R., Nauciene, Z., Ciapaite, J., \& Mildaziene, V. (2010). Acute temperature resistance threshold in heart mitochondria: Febrile temperature activates function but exceeding it collapses the membrane barrier. International Journal of Hyperthermia, 26(1), 56-66. doi: 10.3109/02656730903262140 